Chapter 4

\title{
Food Phenolic Compounds: Main Classes, Sources and Their Antioxidant Power
}

\author{
Maria de Lourdes Reis Giada \\ Additional information is available at the end of the chapter \\ http://dx.doi.org/10.5772/51687
}

\section{Introduction}

The natural phenolic compounds have received increasing interest in the last years, since a great amount of them can be found in plants and consumption of vegetables and beverages with a high level of such compounds may reduce the risk of development of several diseases due to their antioxidant power, among other factors.

It is known that the metabolism of plants is divided in primary and secondary. The substances that are common to living things and essential to cells maintenance (lipids, proteins, carbohydrates, and nucleic acids) are originated from the primary metabolism. On the other hand, substances originated from several biosynthetic pathways and that are restricted to determined groups of organisms are results of the secondary metabolism [1]. Phenolic compounds are constituted in one of the biggest and widely distributed groups of secondary metabolites in plants [2].

Figure 1 shows the inter-relationships between the primary and secondary metabolism in plants.

Biogenetically, phenolic compounds proceed of two metabolic pathways: the shikimic acid pathway where, mainly, phenylpropanoids are formed and the acetic acid pathway, in which the main products are the simple phenol [3]. Most plants phenolic compounds are synthesized through the phenylpropanoid pathway [4]. The combination of both pathways leads to the formation of flavonoids, the most plentiful group of phenolic compounds in nature [3].

Additionally, through the biosynthetic pathways to the flavonoids synthesis, among the not well elucidated condensation and polymerization phases, the condensed tannins or non-hydrolysable tannins are formed. Hydrolysable tannins are derivatives of gallic acid or hexahydroxydiphenic acid [5]. 

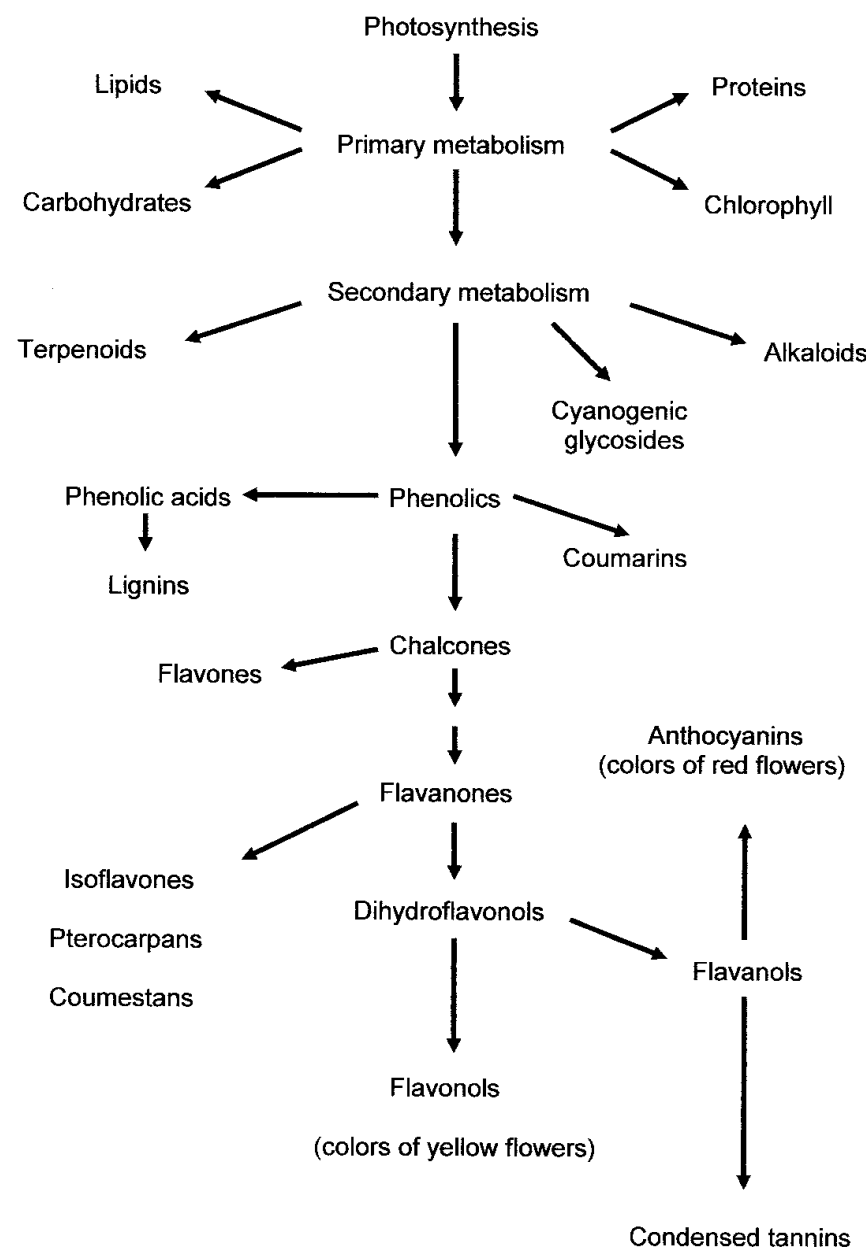

Figure 1. Inter-relationships between the primary and secondary metabolism in plants.

Therefore, phenolic compounds have, as a common characteristic, the presence of at least one aromatic ring hydroxyl-substituted [6]. Another characteristic of these substances is that they are presented commonly bound to other molecules, frequently to sugars (glycosyl residue) and proteins. The existence of phenolic compounds in free form also occurs in plant tissues. However, it is less common, possibly because they are toxic when present in the free state and detoxified, at least in part, when bound.

As a result, phenolic compounds play a role of protection against insects and other animals to the plants. The different types of bond between the glycosyl residue and the flavonoids, 
such as anthocyanin, also lead to the different derivatives that add colors and color gradation to flowers [7].

This way, phenolic compounds are essential to the physiology and cellular metabolism. They are involved in many functions in plants, such as sensorial properties (color, aroma, taste and astringency), structure, pollination, resistance to pests and predators, germinative processes of seed after harvesting and growth as well as development and reproduction, among others [8].

Phenolic compounds can be classified in different ways because they are constituted in a large number of heterogeneous structures that range from simple molecules to highly polymerized compounds.

According to their carbon chain, phenolic compounds can be divided into 16 major classes [9].

The main classes of phenolic compounds regarding to their carbon chain can be seen in Figure 2 .

On the other hand, as to their distribution in nature, phenolic compounds can be divided into three classes: shortly distributed (as simple phenols, pyrocatechol, hydroquinone, resorcinol, Aldehydes derived from benzoic acids that are components of essential oils, such as vanillin), widely distributed (divided in flavonoids and their derivatives, coumarins and phenolic acids, such as benzoic and cinnamic acid and their derivatives) and polymers (tannin and lignin) [10].

Finally, as to the location in the plant (free in the soluble fraction of cell or bound to compounds of cell wall), together with the chemical structure of these substances, phenolic compounds may also be classified as: soluble (such as simple phenol, flavonoids and tannins of low and medium molecular weight not bound to membranes compounds) and insoluble (essentially constituted by condensed tannins, phenolic acids and other phenolic compounds of low molecular weight bound to cell wall polysaccharides or proteins forming insoluble stable complexes). This classification is useful from the nutritional viewpoint, to the extent that the metabolic fate in the gastrointestinal tract and the physiological effects of each group will depend largely on their solubility characteristics. Insoluble phenolic compounds are not digested and may be partially or fully recovered quantitatively in the feces, while a part of the soluble can cross the intestinal barrier and be found in the blood, unchanged or as metabolites [3].

The antioxidant activity of food phenolic compounds is of nutritional interest, since it has been associated with the potentiation of the promoting effects of human health through the prevention of several diseases [11]. Additionally, in some cases, these compounds may also be used with therapeutic purposes due to their pharmacological properties [12]. Many phenolic compounds with low molecular weight, such as thymol, are used in medicine as antiseptic due to its toxicity [7].

However, the antioxidant activity of phenolic compounds depends largely on the chemical structure of these substances [2]. Among the phenolic compounds with known antioxidant activity, flavonoids, tannins chalcones and coumarins as well as phenolic acids are highlighted. 


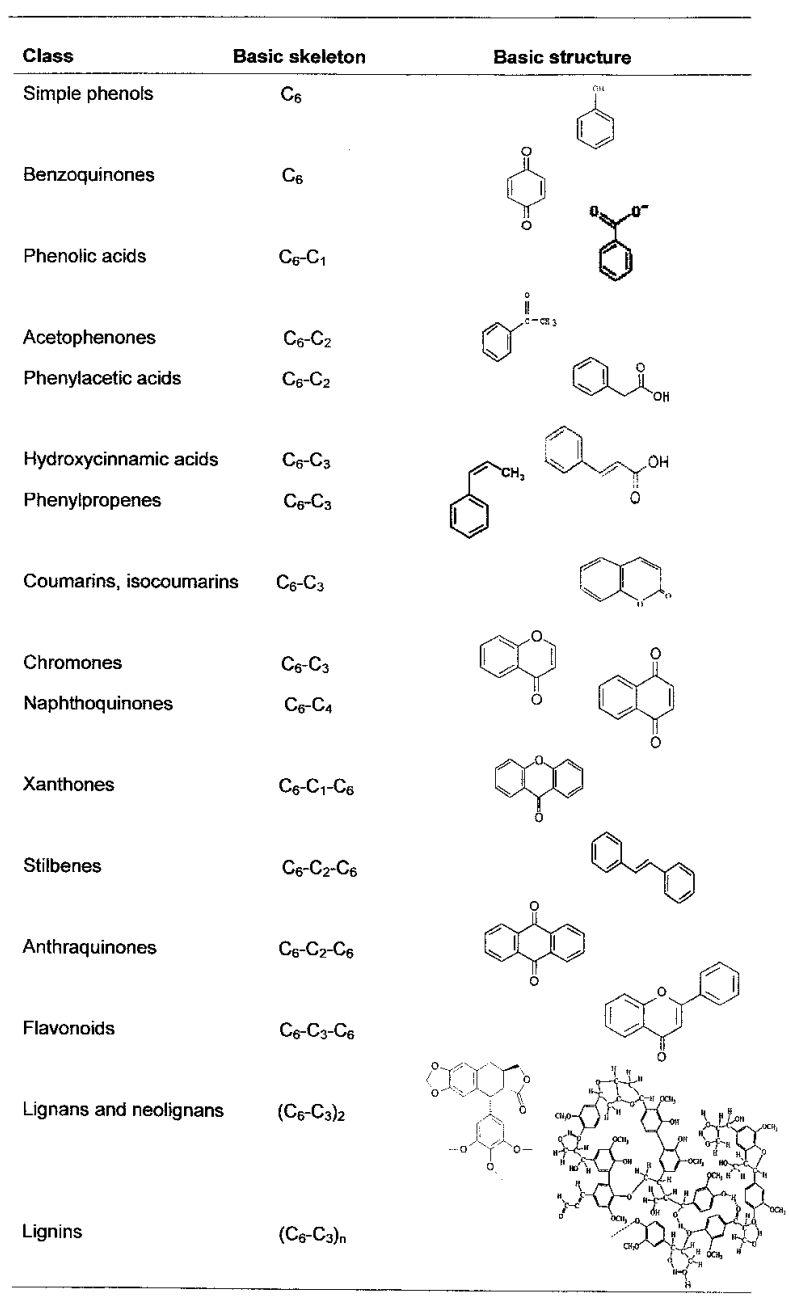

Figure 2. Main classes of phenolic compounds regarding to their carbon chain.

\section{Main Classes}

\subsection{Flavonoids}

According to the degree of hydroxylation and the presence of a $\mathrm{C}_{2}-\mathrm{C}_{3}$ double bond in the heterocycling pyrone ring, flavonoids can be divided into 13 classes [3], the most important being represented by the flavonols, flavanols, flavones, isoflavones, anthocyanidins or anthocyanins and flavanones [2]. Within these classes there are many structural varia- 
tions according to the degree of hydrogenation and hydroxylation of the three ring systems of these compounds. Flavonoids also occur as sulfated and methylated derivatives, conjugated with monosaccharides and disaccharides and forming complexes with oligosaccharides, lipids, amines, carboxylic acids and organic acids, being known approximately 8000 compounds [13].

The basic chemical structures of the main classes of flavonoids are presented in Figure 3.

Flavonoid

Figure 3. Chemical structures of the main classes of flavonoids.

While members of certain classes of flavonoids (eg., flavonones) are colorless, the other (eg, anthocyanins) are always colored, such as flowers pigments and other plant parts [7].

Flavonoids are important constituents of the human diet [14, 15], and are the most widely distributed phenolic compounds in plant foods and also the most studied ones [10]. 
It is known that flavonoids are among the most potent antioxidants from plants. The excellent antioxidant activity of these substances is related to the presence of hydroxyl groups in positions $3^{\prime}$ and 4 ' of the $\mathrm{B}$ ring, which confer high stability to the formed radical by participating in the displacement of the electron, and a double bond between carbons $C_{2}$ and $C_{3}$ of the ring $C$ together with the carbonyl group at the $C_{4}$ position, which makes the displacement of an electron possible from the ring B. Additionally, free hydroxyl groups in position 3 of ring $\mathrm{C}$ and in position 5 of ring $\mathrm{A}$, together with the carbonyl group in position 4 , are also important for the antioxidant activity of these compounds [16]. However, the effectiveness of the flavonoids decreases with the substitution of hydroxyl groups for sugars, being the glycosides less antioxidants than their corresponding aglycons [17].

\subsection{Tannins}

Tannins are phenolic compounds of molecular weight from intermediate to high (500-3000 D) [3] and can be classified into two major groups: hydrolysable tannins and non-hydrolysable or condensed tannins [18]. There is a third group of tannins, phlorotannins, which are only found in brown seaweeds and are not commonly consumed by humans [19].

The hydrolysable tannins have a center of glucose or a polyhydric alcohol partially or completely esterified with gallic acid or hexahydroxydiphenic acid, forming gallotannin and ellagitannins, respectively [20]. These metabolites are readily hydrolyzed with acids, bases or enzymes. However, they may also be oxidatively condensed to other galoil and hexahydroxydiphenic molecules and form polymers of high molecular weight. The best known hydrolysable tannin is the tannic acid, which is a gallotannin consisting of a pentagalloyl glucose molecule that can additionally be esterified with another five units of gallic acid [10].

The condensed tannins are polymers of catechin and/or leucoanthocyanidin, not readily hydrolyzed by acid treatment, and constitute the main phenolic fraction responsible for the characteristics of astringency of the vegetables. Although the term condensed tannins is still widely used, the chemically more descriptive term "proanthocyanidins" has gained more acceptance. These substances are polymeric flavonoids that form the anthocyanidins pigments. The proanthocyanidins most widely studied are based on flavan-3-ols (-)-epicatechin and (+)-catechin [5].

The chemical structures of casuarictin (hydrolysable tannin) and proanthocyanidins (nonhydrolysable or condensed tannins) are shown in Figure $4 \mathrm{~A}$ and 4B, respectively.

Although the antioxidant activity of tannins has been much less marked than the activity of flavonoids, recent researches have shown that the degree of polymerization of these substances is related to their antioxidant activity. In condensed tannins and hydrolysable (ellagitannins) of high molecular weight, this activity can be up to fifteen to thirty times superior to those attributed to simple phenols [16]. 
(A)

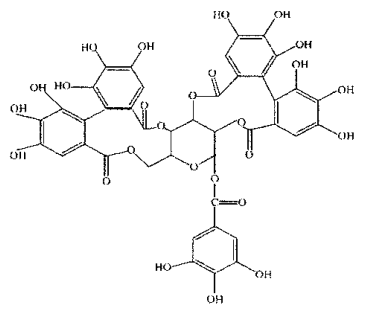

Casuarictin (ellagitannin)
(B)

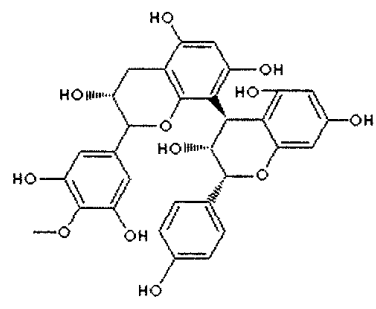

Proanthocyanidins

Figure 4. Chemical structures of hydrolysable tannin (A) and non-hydrolysable or condensed tannins (B).

\subsection{Chalcones and Coumarins}

The chalcones are intermediate in the biosynthesis of flavonoids, being the phloretin and its glucoside phloridzin (phloretin 2'-o-glucose), as well as the chalconaringenin and the arbutin, the most frequently found in foods. The phloretin and phloridzin are characteristics of apples, as well as the chalconaringenin is characteristic of tomatoes and arbutin of pears. However, arbutin is also found in strawberries, wheat and its derivatives, as well as in trace amounts in tea, coffee, red wine and broccoli. In some species of plants, the main pigments of yellow flowers are chalcones [21].

Figure 5 shows the chemical estructures of the main chalcones.

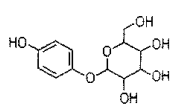

Arbutin

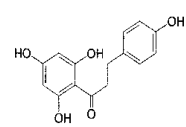

Phloretin

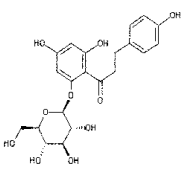

Phloridzin

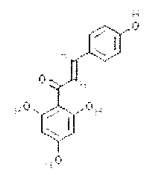

Chalconaringenin

Figure 5. Chemical structures of the main chalcones.

Like the other phenylpropanoids, coumarins constitute a class of secondary metabolites of plants derivatives from cinnamic acid by cyclization of the side chain of the $o$-coumaric acid [22]. These substances are more common in nature in the form of glycosides, such as umbelliferone, esculetin and scopoletin, and are mainly found in olive oil, oats and spices [3].

The chemical structures of the main coumarins can be seen in Figure 6. 
<smiles>O=c1ccc2ccc(O)cc2o1</smiles>

umbelliferone<smiles>O=c1ccc2cc(O)c(O)cc2o1</smiles>

esculetin<smiles>COc1cc2ccc(=O)oc2cc1O</smiles>

scopoletin

Figure 6. Chemical structures of the main coumarins.

Although the data are still limited, it is known that chalcones and coumarins have antioxidant activity [23].

\subsection{Phenolic acids}

Phenolic acids can be divided into two groups: benzoic acids and cinnamic acids and derivatives thereof. The benzoic acids have seven carbon atoms $\left(\mathrm{C}_{6}-\mathrm{C}_{1}\right)$ and are the simplest phenolic acids found in nature. Cinnamic acids have nine carbon atoms $\left(\mathrm{C}_{6}-\mathrm{C}_{3}\right)$, but the most commonly found in vegetables are with seven. These substances are characterized by having a benzenic ring, a carboxylic group and one or more hydroxyl and/or methoxyl groups in the molecule [24].

The general formulas and names of the main benzoic and cinnamic acids are found in Figures 7 and 8, respectively.

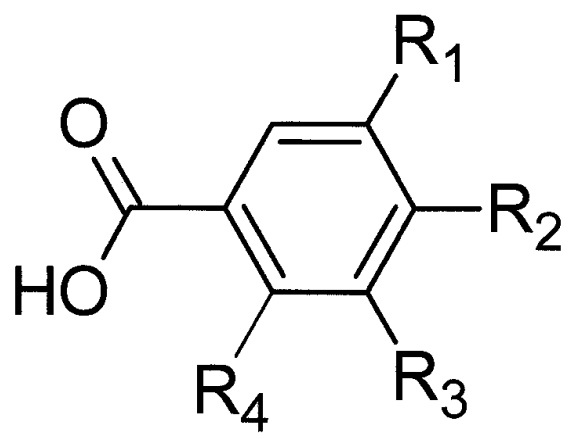

Salicylic acid $\left(\mathrm{R}_{4}=\mathrm{OH}, \mathrm{R}_{1}, \mathrm{R}_{2}, \mathrm{R}_{3}=\mathrm{H}\right)$;

Gentisic acid $\left(\mathrm{R}_{1}, \mathrm{R}_{3}=\mathrm{OH} ; \mathrm{R}_{2}, \mathrm{R}_{4}=\mathrm{H}\right)$;

p-Hydroxybenzoic acid $\left(\mathrm{R}_{2}=\mathrm{OH}, \mathrm{R}_{1}, \mathrm{R}_{3}, \mathrm{R}_{4}=\mathrm{H}\right)$;

Protocatechuic acid $\left(\mathrm{R}_{1}, \mathrm{R}_{2}=\mathrm{OH} ; \mathrm{R}_{3}, \mathrm{R}_{4}=\mathrm{H}\right)$;

Vanillic acid $\left(\mathrm{R}_{1}=\mathrm{OCH}_{3}, \mathrm{R}_{2}=\mathrm{OH} ; \mathrm{R}_{3}, \mathrm{R}_{4}=\mathrm{H}\right)$;

Gallic acid $\left(\mathrm{R}_{1}, \mathrm{R}_{2}, \mathrm{R}_{3}=\mathrm{OH} ; \mathrm{R}_{4}=\mathrm{H}\right)$;

Syringic acid $\left(\mathrm{R}_{1}, \mathrm{R}_{3}=\mathrm{OCH}_{3} ; \mathrm{R}_{2}=\mathrm{OH} ; \mathrm{R}_{4}=\mathrm{H}\right)$

Figure 7. The general formulas and names of the main benzoic acids. 
In the group of benzoic acids the ones that stand out are protocatechuic acids, vanillic acids, syringic acid, gentisic acid, salicylic acid, p-hydroxybenzoic acid and gallic acid [3].

Among the cinnamic acids, $p$-coumaric, ferulic, caffeic and sinapic acids are the most common in nature [24].

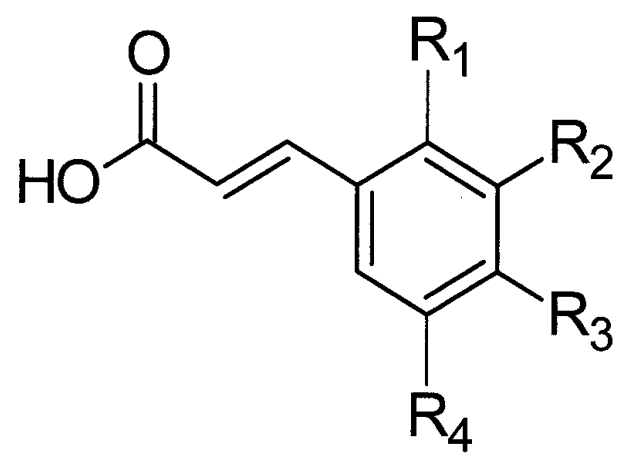

$$
\begin{aligned}
& \text { Ceramic acid }\left(\mathrm{R}_{1}=\mathrm{R}_{2}=\mathrm{R}_{3}=\mathrm{R}_{4}=\mathrm{H}\right) \\
& o \text {-Coumaric acid }\left(\mathrm{R}_{1}=\mathrm{OH} ; \mathrm{R}_{2}, \mathrm{R}_{3}, \mathrm{R}_{4}=\mathrm{H}\right) \\
& m \text {-Coumaric acid }\left(\mathrm{R}_{2}=\mathrm{OH} ; \mathrm{R}_{1}, \mathrm{R}_{3}, \mathrm{R}_{4}=\mathrm{H}\right) \\
& p \text {-Coumaric acid }\left(\mathrm{R}_{3}=\mathrm{OH} ; \mathrm{R}_{1}, \mathrm{R}_{2}, \mathrm{R}_{4}=\mathrm{H}\right) \\
& \text { Caffeic acid }\left(\mathrm{R}_{2}=\mathrm{R}_{3}=\mathrm{OH} ; \mathrm{R}_{1}, \mathrm{R}_{4}=\mathrm{H}\right) \\
& \text { Ferulic acid }\left(\mathrm{R}_{2}=\mathrm{OCH}_{3} ; \mathrm{R}_{3}=\mathrm{OH} ; \mathrm{R}_{1}, \mathrm{R}_{4}=\mathrm{H}\right) \\
& \text { Sinapic acid }\left(\mathrm{R}_{2}=\mathrm{R}_{4}=\mathrm{OCH}_{3}, \mathrm{R}_{3}=\mathrm{OH} ; \mathrm{R}_{1}=\mathrm{H}\right)
\end{aligned}
$$

Figure 8. The general formulas and names of the main cinnamic acids.

Cinnamic acids rarely found free in plants. They are generally in the form of esters, along with a cyclic alcohol-acid, such as quinic acid to form the isochlorogenic acid, neochlorogenic acid, cripto chlorogenic acid and chlorogenic acid, an caffeoyl ester, which is the most important combination [10].

Figure 9 shows the chemical structure of chlorogenic acid.

Phenolic acids may be about one-third of the phenolic compounds in the human's diet [24]. It is known that these substances and their esters have a high antioxidant activity, especially hydroxybenzoic acid, hydroxycinnamic acid, caffeic acid and chlorogenic acid, and although other characteristics also contribute to the antioxidant activity of phenolic acids and their esters, this activity is usually determined by the number of hydroxyl groups found in the molecule thereof. In general, the hydroxylated cinnamic acids are more effective than their benzoic acids counterparts [16].

Despite the antioxidant activity of phenolic compounds and their possible benefits to human health, until the beginning of the last decade, most studies on these substances occurred in relation to their deleterious effects. Tannins, one of the major components of this group, due to the large number of hydroxyl groups contained therein, among other functional groups (1 
to 2 per $100 \mathrm{D}$ ), are capable of forming strong complexes with proteins, starch and other molecules, particularly digestive enzymes, reducing the digestibility of the feed. Likewise, by joining with their hydroxyl and carbonyl groups, tannins have the ability to chelate divalent cations, especially Fe and Zn, reducing the bioavailability of these minerals [10].<smiles>O=C(/C=C/c1ccc(O)c(O)c1)O[C@H]1C[C@@](O)(C(=O)O)C[C@H](O)[C@H]1O</smiles>

Figure 9. Chemical structure of chlorogenic acid.

Although phenolic compounds are traditionally considered antinutrients, and until the moment as non-nutrients because deficiency states are unknown for them, in recent years they have been seen as a group of micro-nutrients in the vegetable kingdom, which are important part of human and animal diet. The condensed and hydrolysable tannins (ellagitannins) of high molecular weight, since they are not absorbed by the mucosa, they have been regarded as insoluble antioxidants that may have high antioxidant activity in the gastrointestinal tract, protecting proteins, lipids and carbohydrates from oxidative damage during digestion [25].

Researches have also suggested that regular consumption of phenolic compounds directly from plant foods may be more effective in combating oxidative damage in our body than in the form of dietary supplement [26]. This can be explained by the possible synergistic interactions among food phenolic compounds, increasing the antioxidant capacity of these substances..

This way, the content of phenolic compounds and the antioxidant power of a wide variety of plant foods have been investigated.

\section{Sources and their antioxidant power}

Table 1 shows the mean content of total phenolic compounds (mg/ $100 \mathrm{~g}$ of sample) of some plant foods. 


\section{Source}

Total phenolics (mg\%)

Reference

\section{Cereals and legumes}

\begin{tabular}{|c|c|c|}
\hline \multicolumn{3}{|l|}{ Cereals and legumes } \\
\hline Cowpea (V. unguicuata), brown & 100 & 27 \\
\hline Soyabean & 414 & 28 \\
\hline Oat & 352 & 29 \\
\hline Wheat flour & 184 & 30 \\
\hline \multicolumn{3}{|l|}{ Vegetables } \\
\hline Black carrot & 68 & 31 \\
\hline Broccoli & 88 & 31 \\
\hline Brussels sprouts & 69 & 31 \\
\hline Cabbage, white & 76 & 32 \\
\hline Cabbage, red & 186 & 32 \\
\hline Endive & 92 & 32 \\
\hline Kale & 136 & 33 \\
\hline Lettuce & 107 & 32 \\
\hline Potato & 150 & 31 \\
\hline Spinach & 112 & 32 \\
\hline Tomato & 68 & 32 \\
\hline Yam & 92 & 31 \\
\hline \multicolumn{3}{|l|}{ Herbs and spices } \\
\hline Basil & 4425 & 34 \\
\hline Chilli, green & 107 & 32 \\
\hline Chilli, red & 277 & 32 \\
\hline Coriander & 374 & 31 \\
\hline Garlic & 145 & 31 \\
\hline Ginger & 221 & 31 \\
\hline Leek & 85 & 32 \\
\hline Mint & 400 & 31 \\
\hline Onion, white & 269 & 35 \\
\hline Onion, yellow & 164 & 35 \\
\hline Onion, red & 428 & 35 \\
\hline Pepper, black & 1600 & 36 \\
\hline Pepper, white & 800 & 36 \\
\hline
\end{tabular}




\section{Source}

Shallot

Sweet onion

Thyme

Turmeric

\section{Fruits}

\begin{tabular}{|c|c|c|}
\hline Apple, green & 118 & 38 \\
\hline Apple, red & 125 & 38 \\
\hline Apple, yellow & 100 & 38 \\
\hline Blueberry & 362 & 39 \\
\hline Cherry, sour & 156 & 40 \\
\hline Cherry,sweet & 79 & 38 \\
\hline Grape, black & 213 & 38 \\
\hline Grape, white & 184 & 38 \\
\hline Grapefruit & 893 & 41 \\
\hline Guava, pink flesh & 247 & 42 \\
\hline Guava, white flesh & 145 & 42 \\
\hline Kiwi & 791 & 43 \\
\hline Lemon & 843 & 41 \\
\hline Lime & 751 & 41 \\
\hline Litchi & 60 & 44 \\
\hline Nectarine, white flesh & 38 & 45 \\
\hline Nectarine, yellow flesh & 25 & 45 \\
\hline Orange, sweet & 1343 & 41 \\
\hline Peach, white flesh & 53 & 45 \\
\hline Peach, yellow flesh & 35 & 45 \\
\hline Pear & 125 & 38 \\
\hline Pineapple & 94 & 44 \\
\hline Plum, black & 88 & 44 \\
\hline Plum, red & 73 & 44 \\
\hline Pomegranate & 147 & 44 \\
\hline Pomelo & 57 & 44 \\
\hline Raspberry, black & 670 & 46 \\
\hline
\end{tabular}

\section{Total phenolics (mg\%)}

1718

142

1646

176

31
Reference

35

35

37

5




\begin{tabular}{lcc}
\hline Source & Total phenolics (mg\%) & Reference \\
\hline Raspberry, red & 342 & 46 \\
\hline Raspberry, yellow & 426 & 46 \\
\hline Strawberry & 199 & 47 \\
\hline \hline Others & 1305 & 48 \\
\hline Roasted cocoa bean & 994 & 48 \\
\hline Cocoa liquor & 896 & 48 \\
\hline Alkalised cocoa powder & 349 & 48 \\
\hline Baking chocolate & 242 & 49 \\
\hline Red wine & 62 & 50 \\
\hline Tea, black & 83 & 50 \\
\hline Tea, green & 188 & 51
\end{tabular}

Table 1. Total phenolic compounds content of some plant foods.

As can be seen in Table 1, phenolic compounds are widely distributed in plant foods.

Cocoa, potato, yam, tomato, kale, Brussels sprouts, broccoli and others dark green leafy and brightly-colored vegetables as well as legumes and cereals, in addition to spices and fruits such as cherries and citrus, are particularly rich in phenolic compounds. Red wine also has a high concentration of phenolic compounds. It is known that the abundant phenolic compounds in red wine are anthocyanin $[6,52]$. The green and black teas have been extensively studied, since they may contain up to $30 \%$ of their dry weight as phenolic compounds [53]. Coffee is also rich in phenolic compounds, especially chlorogenic acid. It has about $7 \%$ of the dry weight of the grains [24] and 15\% of the dry instant coffee as phenolic compounds [54].

Although in some studies a few statistically significant correlations were found between the levels of total phenolic compounds and antioxidant power of foods, in others the total phenolics content of samples was highly correlated with the antioxidant capacity. On the other hand, there are still no standard methods and approved for determining the antioxidant power in vitro. The several available tests for this purpose involve different mechanisms of antioxidant defense system, from the chelation of metal ions to the measure of preventing oxidative damage to biomolecules, and offer distinct numerical results that are difficult to compare. Because of this, studies have used different methods to evaluate the antioxidant capacity of the studied sample, such as ABTS (2,2-azino-bis-3-ethylbenzothiazoline-6-sulfonic acid radical assay), DPPH (2,2-diphenyl-picrylhydrazyl radical assay), FRAP (Ferric Reducing/Antioxidant Power assay) and ORAC (Oxygen Radical Absorbance Capacity assay), among others tests. 
By determining the content of total phenolic compounds and ability to reduce $\mathrm{FeCl}_{3}$ as well as DPPH free radical of some commonly consumed and underutilized tropical legumes [27], it was concluded that one of the commonly consumed cowpea Vigna unguiculata (brown) as well as underutilized legumes C. cajan (brown) and S. sternocarpa could be considered as functional foods due to their relatively higher antioxidant power, which could be as a result of their relative higher total phenolics content. In a similar way, evaluating the antioxidant capacity of twenty soybean hybrids by DPPH assay and their total phenolics content [28], it was concluded that the two cultivars that showed the highest contents of total phenolics also showed the highest antioxidant powers.

Among cereals, milled oat groat pearlings, trichomes, flour, and bran were evaluated as to their antioxidant capacity against the oxidation of $R$-phycoerythrin protein in the ORAC assay, as well as against the oxidation of low density lipoproteins (LDL) [55]. In both the methods applied the antioxidant capacity of the fractions of oats was in the following order: pearlings $>$ flour $>$ trichome $=$ bran. It was concluded through this study that a part of oat antioxidants, which is rich in phenolic compounds [29], is probably heat-labile because greater antioxidant power was found among the non-steam-treated pearlings. In another study, ten varieties of soft wheat were compared as to their content of total phenolic compounds and antioxidant capacity [30]. Important DPPH, oxygen, hydroxyl and ABTS radical removal capacity was found in all the studied varieties and the content of total phenolics of the samples showed correlation with their antioxidant power in DPPH, ORAC and ABTS assays.

On the other hand, searching the antioxidant capacity of vegetables in the genus Brassica and the best solvent (ethanol, acetone and methanol) for the extraction of their phenolic compounds [56], the results showed that the solvent used significantly affects the phenolics content and the properties of the studied extract. Methanolic extract showed the largest content of total phenolics of broccoli, Brussels sprouts, and white cabbage. In this study, the antioxidant power of the samples was confirmed by different reactive oxygen species and showed to be concentration-dependent. Kale extracts have also been evaluated as to their content of total phenolic compounds and antioxidant capacity [33]. It can be observed that all studied fractions (free and conjugated forms) were able to remove the DPPH radical and that the content of total phenolic compounds of fractions was highly correlated with their antioxidant power.

Herbs and spices are of particular interest, since they have been proved to have high content of phenolic compounds and high antioxidant capacity. The values of Trolox Equivalent Antioxidant Capacity (TEAC) and content of total phenolics were determined for 23 basil accessions [34]. A positive linear relationship was found between the content of total phenolic compounds and the antioxidant power of samples. This study concluded that basils have valuable antioxidant properties for culinary and possible medical application. The concentration of phenolic compounds in peppercorn (black and white), as well as the ability of hydrolyzed and nonhydrolyzed pepper extracts to remove DPPH, superoxide, and hydroxyl radicals [36] were also investigated. The results obtained showed that hydrolyzed and nonhydrolyzed extracts of black pepper contained significantly more phenolic compounds when compared with those of white pepper. For any of these peppers, the hydrolyzed ex- 
tract contained significantly more phenolic compounds in comparison with the nonhydrolyzed extract. A dose-dependent effect was observed for all extracts concerning the power of removing free radical and reactive oxygen species, the black pepper extracts being the most effective. This study concluded that the pepper, especially black, which is an important component in the diet of many sub-Saharan and Eastern countries due to its nutritional importance, can be considered an antioxidant and radical scavenging. However, evaluating the content of phenolic compounds and antioxidant capacity of 14 herbs and spices [37], although a significant correlation has been obtained between the phenolics content and antioxidant capacity of samples, it was found that the trend of the antioxidant capacity was different according to the method applied. The leaves of the species Piper showed the highest antioxidant capacity in both methods studied (Folin-Ciocalteu reagent and FRAP method). Yet, the African mango showed the greatest content of free antioxidant by FRAP method, while by Folin method Piper umbellatum excelled followed by thyme. This study concluded that the antioxidant power of plant samples should be interpreted with caution when measured by different methods. In spite of that fact, regardless of the method used, the samples were rich in antioxidants.

In addition to the studies already mentioned, the antioxidant capacity of 36 plant extracts was evaluated by the $\beta$-carotene and linoleic acid model system [31] and the content of total phenolic compounds of the extracts was determined. Mint, black carrots, and ginger showed high content of total phenolics. The antioxidant capacity calculated as percentage of oxidation inhibition ranged from a maximum of $92 \%$ in turmeric extracts to a minimum of $12.8 \%$ in long melon. Other foods which have high antioxidant capacity $(>70 \%)$ were ginger, mint, black carrots, Brussels sprouts, broccoli, yam, coriander and tomato. The antioxidant power of the samples significantly and positively correlated with their content of total phenolic compounds, allowing the conclusion that the plant foods with high content of phenolic compounds can be sources of dietary antioxidants. In another study, 66 types of plant foods were analyzed as to their content of phenolic compounds and their antioxidant capacity in the ORAC assay [32]. The results showed that the antioxidants composition and concentration varied significantly among the different vegetables. The coriander, Chinese kale, water spinach and red chili showed high content of total phenolics and high antioxidant power.

Due to the growing recognition of their nutritional and therapeutic value, many fruits have also been investigated as to their content of phenolic compounds and antioxidant capacity. By evaluating the antioxidant capacity and total phenolics content, in addition to flavanol and monomeric anthocyanins, it was found from the flesh and peel of 11 apple cultivars [57] that the concentrations of the parameters investigated differed significantly among the cultivars and were higher in the peel in comparison to the flesh. The content of total phenolics and antioxidant capacity were significantly correlated in both flesh and peel. It was concluded that the contribution of phenolics to the antioxidant power in apple peel suggests that peel removal may induce a significant loss of antioxidants. It is also known that one of the most important sources of antioxidants among fruits is small red fruits. By determining the antioxidant capacity of four cultivars of blueberry through three different assays (DPPH, ABTS and FRAP), as well as the content of total phenolic compounds, in addition to flavo- 
noids, anthocyanins and flavan-3-ols [39], it was found that all cultivars contained high content of total phenolics, flavonoids and anthocyanins and lower content of flavan-3-ols. However, significant differences were found in the total phenolics content among the different cultivars and growing seasons. Despite this, the studied cultivars showed high antioxidant power, which was highly correlated with the samples phenolic compounds. Similarly, by checking the content of total phenolics, in addition to flavonoids and anthocyanins, as well as the antioxidant capacity of three cultivars of sour cherries [58], a significant difference was observed in phenolics content among different cultivars and growing seasons. However, the cultivars analyzed showed high antioxidant capacity, which was correlated with the phenolic compounds found in them. In this study significant increases were also found in the content of total phenolic compounds and antioxidant power during the ripening of fruits. Additionally, different solvents were applied for comparing the antioxidant capacity and the yield of total phenolic compounds present in the extracts of sour and sweet cherries [40]. It was found that the solubility of phenolic compounds was more effective in extracts of sweet cherries with use of methanol at 50\% and in extracts of sour cherries with the use of acetone at 50\%. Extracts from lyophilized sour cherries (methanolic and acetone water-mixtures) presented in average twice as high phenolic compounds than ethanolic extracts. The DPPH antiradical efficiency values were higher in the extracts of sour cherries when compared with those of sweet cherries. It was concluded in this work that the strong antioxidant power of extracts of sour cherries is due to the substantial amount of total phenolic compounds present in them and that the fresh sour cherry can be considered as a good dietary source of phenolic compounds. The total phenolics content, total monomeric anthocyanins and antioxidant capacities of 14 wild red raspberry accessions were also examined [59]. In this study, more two cultivars were included in the investigation to determine the variation between wild and cultivated raspberries. Antioxidant capacity of fruits was evaluated by both FRAP and TEAC assays. Significant variability was found for total phenolics, total monomeric anthocyanins and antioxidant capacity of wild raspberries. Nevertheless, the results indicated that some of the wild accessions of red raspberries have higher antioxidant power and phytonutrients content than existing domesticated cultivars. Finally, two strawberry cultivars were studied as to their content of total phenolic compounds and antioxidant capacity in different ripeness stages [47]. It was concluded that despite the berries in general have better taste and be more appreciated at ripe stage, higher contents of total phenolic compounds and antioxidant power were observed at pink stage for both strawberry cultivars studied. Also with respect to the fruits, a less known snake fruit was compared with better known kiwi fruit regarding to their total phenolics content and four radical scavenging (FRAP, ABTS, DPPH and CUPRAC/Cupric Reducing Antioxidant Capacity) ability [43]. It was observed similarity between snake fruit and kiwi fruit in the contents of phenolic compounds as well as antioxidant power in DPPH assay. By this study, it was able to conclude that the two fruits can be applied as antioxidant supplements to the normal diet. Consumption of a combination of both fruits could be recommended in order to obtain the best results. In another study, 25 cultivars, 5 each of white-flesh nectarines, yellow-flesh nectarines, white-flesh peaches, yellow-flesh peaches, and plums at the ripe stage were studied for their total phenolics content and antioxidant capacity by the DPPH and FRAP assays [45]. In 
descending order, the cultivars presenting higher contents of total phenolics were: whiteflesh peaches, plums, yellow-flesh peaches and yellow-flesh nectarines. There was a strong correlation between total phenolics and antioxidant power of nectarines, peaches, and plums. By continuing to study the plum fruits, 20 genotypes of plums were investigated for their antioxidant capacity and total phenolics content [60]. Among the 20 genotypes, a strong correlation was observed between the total phenolics and antioxidant power of the samples, which was determined upon the FRAP assay. It was concluded that phenolic compounds seem to play a significant role in antioxidant value and health benefits of plums. Additionally, Mirabelle plums were examinated for their antioxidant capacity by different assays (DPPH, FRAP, ORAC) and total phenolics content [61]. The antioxidant power of the plum peels, flesh and pits reflected the total phenolics content of the samples with efficacy increasing of the order: peels < flesh < pits across the assays. Peel and flesh of six pear cultivars were also investigated for their antioxidant capacity by DPPH assay and total phenolics content [62]. The results obtained showed that the total phenolics content in the peel can be up to 25 times higher than in the flesh. The peel also showed higher antioxidant power. The pomegranate is another fruit that has been researched. Its peel, mesocarp and juice were evaluated for their antioxidant power by TEAC and FRAP assays as well as total phenolics content [63]. It was found not only high correlation between TEAC and FRAP values, but also with the total phenolics content, which was in the following order: mesocarp > peel > juice. This study demonstrated that selection of raw materials (co-extraction of arils and peel) and pressure, respectively, markedly affected the profile and content of phenolics in the pomegranate juices, underlining the necessity to optimise these parameters for obtaining products with well-defined functional qualities. Studies have also been carried out to quantify the total phenolics content and antioxidant capacity of citrus fruits. Comparing the antioxidant properties of peel (flavedo and albedo) and juice of grapefruit, lemon, lime and sweet orange, four different antioxidant assays (DPPH, Reducing Power, $\beta$-carotene-linoleate Model System and Thiobarbituric Acid Reactive Substances/TBARS) were applied to the volatile and polar fractions of peels and to crude and polar fraction of juices [41]. Phenolic compounds were among the two main antioxidant substances found in all extracts. Peels polar fractions showed the highest contents in phenolics, which probably contribute to the highest antioxidant power found in these fractions. However, peels volatile fractions showed the lowest antioxidant power. In another experiment, grapefruit and sour orange were extracted with five different polar solvents. The total phenolics content of the extracts was determined and the dried fractions were screened for their antioxidant capacity by four different assays (DPPH, Phosphomolybdenum method, Nitroblue tetrazolium/NBT Reduction and Reducing Power) [64]. All citrus extracts showed good antioxidant capacity. The best correlation between total phenolics and radical scavenging activity was observed by DPPH method. It was concluded that the data obtained clearly established the antioxidant power of the studied citrus fruit extracts. Studying the extraction efficiency of five different solvents on the total phenolics content and antioxidant capacities of pomelo and navel oranges by five antioxidant assays (DPPH, ORAC, ABTS, Phospomolybdenum method and Reducing Power) [65], it was found that the total phenolics content of extracts varied according to the solvent used. Significant differences were also found in antioxidant capacity val- 
ues via the same method in different solvents, as well as on the antioxidant capacity of each extract via different methods. Nonetheless, the broad range of activity of the extracts led to the conclusion that multiple mechanisms are responsable for the antioxidant power of the samples and clearly indicated the potential application value of the citrus fruits studied. Finally, the study of the content of phenolic compounds and antioxidant power of tropical fruits such as guava has also been conducted. One white-fleshed and three pink-fleshed of guava were analyzed as to their content of total phenolics, in addition to ascorbic acid and total carotenoids, as well as to their antioxidant capacity [42]. The ABTS, DPPH and FRAP assays were used for determining the antioxidant capacity in methanol and dichloromethane extracts of the samples, while the ORAC assay was used only for determining it in methanol extracts. The results obtained showed that white pulp guava had more total phenolics and ascorbic acid than pink pulp guava. On the other hand, carotenoids were absent in the white pulp guava. In all antioxidant assays the methanol extracts showed good correlation with the content of total phenolics and ascorbic acid, as well as between them, but showed negative correlation with total carotenoids.

In addition to the aforementioned fruits, in the search for new foods rich in phenolic compounds and high antioxidant capacity, unconventional tropical fruits have been widely researched. Accordingly, the Antilles cherry, Barbados cherry or acerola (1063 mg/100 g), camu-camu (1176 mg/100 g), puçá-preto (868 mg/100 g), assai or açaí (454 mg/100 g) and jaboticaba $(440 \mathrm{mg} / 100 \mathrm{~g})$ showed to be rich in phenolic compounds. When testing the antioxidant capacity of these fruits fresh and dry matter by DPPH assay, it was found an association between their antioxidant power and total phenolics content [66]. Similarly, banana passion fruit $(635-1018 \mathrm{mg} / 100 \mathrm{~g})$, cashew $(445 \mathrm{mg} / 100 \mathrm{~g})$ and guava apple (309 mg/ $100 \mathrm{~g}$ ) also showed a high total phenolic content when evaluated by FRAP and ABTS assays. The antioxidant power of these fruits showed a strong correlation with their total phenolics content [67].

Other plant-originated foods studied for their content of phenolic compounds and antioxidant capacities are as follows. The cocoa and chocolate liquor antioxidant capacities as well as monomeric and oligomeric procyanidins were studied [68]. The results obtained showed that the procyanidins content was correlated with the antioxidant capacity, which was determined by the ORAC assay as an indicator for potential biological activity of the samples. However, following the changes in total and individual phenolics content as well as antioxidant capacity during the processing of cocoa beans [48], it can be noted that the loss of phenolic compounds and antioxidant capacity of cocoa vary according to the degree of technological processing. The roasting process and cocoa nib alkalization had the greatest influence on the content of phenolic compounds and antioxidant power. The antioxidant capacity of 107 different Spanish red wines, from different varieties of grapes, aging processes and vintages [69] was also investigated by different methods and the results showed that all samples had an important capacity of removing hydroxyl radical and were able to block the superoxide radical, but with 10 times lower intensity. The wines also showed important protective action on biomarkers of oxidative stress. However, few statistically significant correlations were found between the levels of total phenolics and antioxidant power of the wines and the values of these correlations were very low. In another investi- 
gation, the antioxidant capacities of three Argentine red wines were evaluated by TEAC and FRAP assays. The correlation between antioxidant capacity and content of phenolic compounds as well as between antioxidant capacity and phenolic profile of samples [49] was determined. It can be noted that the wines showed significant antioxidant capacity. However, no significant correlation was found between their antioxidant capacity and total phenolics content. Nevertheless, the canonical correlation and multiple regression analysis showed that the antioxidant capacity of the samples was highly correlated with their profile of phenolic compounds. The results obtained in this study showed the importance of analyzing the phenolic profile of the sample rather than total phenolics to help understand the differences in the antioxidant power of wines, which should be extended to other food products. Among the alcoholic beverages, antioxidant power has also been reported for whiskey, sake and sherries. [70]. In addition to alcoholic beverages, the free radicalscavenging activity and total phenolic content of commercial tea [50] were determined, finding that green tea contained higher content of phenolic compounds than black tea. The antioxidant capacity per serving of green tea was also much higher than that of black tea. However, comparing the content of total phenolics, flavonoids and antioxidant capacity of black tea, green tea, red wine and cocoa by ABTS and DPPH assays [71], it was found that cocoa contains much higher levels of total phenolics and flavonoids per serving than black tea, green tea and red wine. In the two methods applied, the antioxidant power of the samples per serving was found in the following descending order: cocoa, red wine, green tea and black tea. The content of total phenolic compounds and DPPH and ABTS radical removal capacity of coffee extracts obtained by continuous (Soxhlet $1 \mathrm{~h}$ and $3 \mathrm{~h}$ ) and discontinuous (solid-liquid extraction and filter coffeemaker) methods, many solvents (water, methanol, ethanol and their mixtures), successive extractions and water with different pHs (4.5, 7.0 and 9.5) were also evaluated [72]. The coffee extracts with the highest antioxidant capacity were obtained after extraction with water neutral $(\mathrm{pH} 7.0)$ in the filter coffeemaker $(24 \mathrm{~g}$ spent coffee per $400 \mathrm{~mL}$ water). In addition, the drink degreasing and lyophilization of the extract permitted to obtain coffee extract powder with high antioxidant power, which can be used as an ingredient or additive in the food industry with potential for preservation and functional properties.

It is also know that tamarind, canola, sesame, linseed and sunflower seeds are other possible sources of phenolic compounds [73] and have high antioxidant capacity. The antioxidant capacity of the striped sunflower seed cotyledon extracts, obtained by sequential extraction with different polarities of solvents, was determined by three in vitro methods: FRAP, DPPH and ORAC [74]. In the three methods applied, the aqueous extract showed higher antioxidant capacity than the ethanolic. When compared with the synthetic antioxidant Butylated Hydroxyl Toluene (BHT), the antioxidant power of the aqueous extract varied from $45 \%$ to $66 \%$, according to the used method. It was concluded in this study that the high antioxidant power found for the aqueous extract of the studied sunflower seed suggests that the intake of this seed may prevent in vivo oxidative reactions responsible for the development of several diseases. 


\section{Conclusion}

Phenolic compounds are widely distributed in plant foods (cereals, vegetables, fruits and others), stressing among them the flavonoids, tannins, chalcones, coumarins and phenolic acids. Although some studies have shown few statistically significant correlations between the levels of total phenolics and antioxidant capacity in foods, in others the content of total phenolic compounds was highly correlated with the antioxidant power of samples. Among the plant foods with a high content of phenolic compounds and antioxidant capacity, we can stand out the dark green leafy and brightly-colored vegetables, in addition to cocoa, soyabean, spices and fruits such as cherries and citrus.

\section{Author details}

Maria de Lourdes Reis Giada*

Address all correspondence to: mlgiada@nutricao.ufrj.br

Department of Basic and Experimental Nutrition, Institute of Nutrition, Health Sciences Center, Federal University of Rio de Janeiro, Brazil

\section{References}

[1] Vickery, M. L., \& Vickery, B. (1981). Secondary plant metabolism. London: MacMillan.

[2] Scalbert, A, \& Williamson, G. (2000). Dietary intake and bioavailability of polyphenols. Journal of nutrition, 130, 2073S-2085S.

[3] Sánchez-Moreno, C. (2002). Compuestos polifenólicos: estructura y classificación: presencia en alimentos y consumo: biodisponibilidad y metabolismo. Alimentaria, $329,19-28$.

[4] Hollman, P. C. H. (2001). Evidence for health benefits of plant phenols: local or systemic effects? Journal of the Science of Food and Agriculture, 81(9), 842-852.

[5] Stafford, H. A. (1983). Enzymic regulation of procyanidin bisynthesis, lack of a flav-3-en-3-ol intermediate. Phytochemistry, 22, 2643-2646.

[6] Morton, L. W., Cacceta, R. A. A., Puddey, I. B., \& Croft, K. D. (2000). Chemistry and biological effects of dietary phenolic compounds: relevance to cardiovascular disease. Clinical and Experimental Pharmacology and Physiology, 27(3), 152-159.

[7] Harborne, J. B. (1980). Plant phenolics. In: Bell EA, Charlwood BV, Archer B. (ed.) Secondary plant products. Berlin: Springer-Verlag, 330-402. 
[8] Tomás-Barberán, F. A., \& Espín, J. C. (2001). Phenolic compounds and related enzymes as determinants of quality in fruits and vegetables. Journal of the Science of Food and Agriculture, 81(9), 853-876.

[9] Harborne, J. B. (1989). Methods in plant biochemistry. In: Dey PM, Harborne JB. (ed.) Plant phenolics. London: Academic Press, 1.

[10] Bravo, L. (1998). Polyphenols: chemistry, dietary sources, metabolism and nutritional significance. Nutrition Reviews, 56(11), 317-333.

[11] Lampe, J. W. (1999). Health effects of vegetables and fruit: assessing mechanisms of action in human experimental studies. The American Journal of Clinical Nutrition, 70, 475S-490S.

[12] Percival, M. (1998). Antioxidants. Clinical Nutrition Insights, 10, 1-4.

[13] Duthie, G. G, Gardner, P. T, \& Kyle, J. A. M. (2003). Plant polyphenols: are they the new magic bullet? Proceedings of the Nutrition Society, 62(3), 599-603.

[14] Hertog, M. G. L., Hollman, P. C. H., \& Venema, D. P. (1992). Optimization of a quantitative HPLC determination of potentially anticarcinogenic flavonoids in vegetables and fruits. Journal of Agricultural and Food Chemistry, 40(9), 1591-1598.

[15] Jovanovic, S. V., Steenken, S., Tosic, M., Marjanovic, B., \& Simic, M. G. (1994). Flavonoids as antioxidants. Journal of the American Chemical Society, 116(11), 4846-4851.

[16] Sánchez-Moreno, C. (2002 ). Compuestos polifenólicos: efectos fisiológicos: actividad antioxidante. Alimentaria, 329, 29-40.

[17] Rice-Evans, C., Miller, N. J., \& Paganga, G. (1996). Structure-antioxidant activity relationships of flavonoids and phenolic acids. Free Radical Biology and Medicine, 20(7), 933-956.

[18] Chung, K. T., Wong, T. Y., Wei, C. I., Huang, Y. W., \& Lin, Y. (1998). Tannins and human health: a review. Critical Reviews in Food Science and Nutrition, 38(6), 421-464.

[19] Ragan, M. A., \& Glombitza, K. (1986). Phlorotannin: Brown algal polyphenols. Progress in Physiological Research, 4, 177-241.

[20] Okuda, T., Yoshida, T., \& Hatano, T. (1995). Hidrolyzable tannins and related polyphenols. Fortschritte der Chemie organischer Naturstoffe, 66, 1-117.

[21] Karakaya, S. (2004). Bioavailability of phenolic compounds. Critical Reviews in Food Science and Nutrition, 44(6), 453-464.

[22] Matern, V., Lüer, P., \& Kreusch, D. (1999). Biosynthesis of coumarins. In: Barton D, Nakanishi K, Meth-Cohn O, Sankawa V. (ed.) Comprehensive natural products chemistry: polyketides and other secondary metabolites including fatty acids and their derivatives. Amsterdam: Elsevier Science, 623-637.

[23] Pratt, D. E., \& Hudson, B. J. F. (1990). Natural antioxidant no exploited commercially. In: Hudson BJF. (ed.) Food antioxidants. London: Elsevier Applied sciences, 171-180. 
[24] Yang, C. S., Landau, J. M., Huang, M. T., \& Newmark, H. L. (2001). Inhibition of carcinogenesis by dietary polyphenolic compounds. Annual Review of Nutrition, 21, 381-406.

[25] Martínez-Valverde, I., Periago, M. J., \& Ros, G. (2000). Significado nutricional de los compuestos fenólicos de la dieta. Archivos Latinoamericanos de Nutrición, 50(1), 5-18.

[26] Martin, K. R., \& Appel, C. L. (2010). Polyphenols as dietary supplements: A doubleedged sword. Nutritional and Dietary Supplements, 2, 1-12.

[27] Oboh, G. (2006). Antioxidant properties of some commonly consumed and underutilized tropical legumes. European Food Research and Technology, 224(1), 61-65.

[28] Malencić, D., Popović, M., \& Miladinović, J. (2007). Phenolic content and antioxidant properties of soybean (Glycine max (L.) Merr.) seeds. Molecules, 12(3), 576-581.

[29] Kovácová, M., \& Malinová, E. (2007). Ferulic and coumaric acids, total phenolic compounds and their correlation in selected oat genotypes. Czech Journal of Food Sciences, 25(6), 325-332.

[30] Lv, J., Yu, L., Lu, Y., Nui, Y., Liu, L., Costa, J., \& Yu, L. (2012). Phytochemical compositions, and antioxidant properties, and antiproliferative activities of wheat flour. Food Chemistry, doi: 10.1016/j.foodchem.2012.04.141.

[31] Kaur, C., \& Kapoor, H. C. (2002). Anti-oxidant activity and total phenolic content of some Asian vegetables. International Journal of Food Science and Technology, 37(2), 153-161.

[32] Isabelle, M., Lee, B. L., Lim, M. T., Koh, W. P., Huang, D., \& Ong, C. N. (2010). Antioxidant activity and profiles of common vegetables in Singapore. Food Chemistry, 120(4), 993-1003.

[33] Ayaz, F. A., Hayirhoglu-Ayaz, S., Alpay-Karaoglu, S., Grúz, J., Valentová, K., Ulrichová, J., \& Strnad, M. (2008). Phenolic acid contents of kale (Brassica oleraceae L. var. acephala DC.) extracts and their antioxidant and antibacterial activities. Food Chemistry, 107(1), 19-25.

[34] Javanmardi, J., Stushnoff, C., Locke, E., \& Vivanco, J. M. (2003). Antioxidant activity and total phenolic content of Iranian Ocimum accessions. Food Chemistry, 83(4), 547-550.

[35] Lu, X., Wang, J., Al-Qadiri, H. M., Ross, C. F., Powers, J. R., Tang, J., \& Rasco, BA. (2011). Determination of total phenolic content and antioxidant capacity of onion (Allium cepa) and shallot (Allium oschaninii) using infrared spectroscopy. Food Chemistry, 129(2), 637-644.

[36] Agbor, G. A., Vinson, J. A., Oben, J. E., \& Ngogang, J. Y. (2006). Comparative analysis of the in vitro antioxidant activity of white and black pepper. Nutrition Research, 26(12), 659-663. 
[37] Agbor, G. A., Oben, J. E., Ngogang, J. Y., Xinxing, C., \& Vinson, J. A. (2005). Antioxidant capacity of some herbs/spices from Cameroon: A comparative study of two methods. Journal of Agricultural and Food Chemistry, 53(17), 6819-6824.

[38] Marinova, D., Ribarova, F., \& Atanassova, M. (2005). Total phenolics and total flavonoids in Bulgarian fruits and vegetables. Journal of the University of Chemical Technology and Metallurgy, 40(3), 255-260.

[39] Dragović-Uzelac, V., Savić, Z., Brala, A., Levaj, B., Kovacević, D. B., \& Biško, A. (2010). Evaluation of phenolic content and antioxidant capacity of blueberry cultivars (Vaccinium corymbosum L.) grown in the Northwest Croatia. Food Technology and Biotechnology, 48(2), 214-221.

[40] Melichácová, S., Timoracká, M., Bystrická, J., Vollmannová, A., \& Céry, J. (2010). Relation of total antiradical activity and total polyphenol content of sweet cherries (Prunus avium L.) and tart cherries (Prunus cerasus L.). Acta Agriculturae Slovenica, 95(1), 21-28.

[41] Guimarães, R., Barros, L., Barreira, J. C. M., Sousa, M. J., Carvalho, A. M., \& Ferreira, I. C. F. R. (2010). Targeting excessive free radicals with peels and juices of citrus fruits: grapefruit, lemon, lime and Orange. Food and Chemical Toxicology, 48(1), 99-106.

[42] Thaipong, K., Boonprakob, U., Crosby, K., Zevallos, L. C., \& Byrne, D. H. (2006). Comparison of ABTS, DPPH, FRAP, and ORAC assays for estimating antioxidant activity from guava fruit extracts. Journal of Food Composition and Analysis, 19(6), 669-675.

[43] Gorinstein, S., Haruenkit, R., Poovarodom, S., Park, Y. S., Vearasilp, S., Suhaj, M., Ham, K. S., Heo, B. G., Cho, J. Y., \& Jang, H. G. (2009). The comparative characteristics of snake and kiwi fruits. Food and Chemical Toxicology, 47(8), 184-1891.

[44] Fu, L., Xu, B. T., Xu, X. R., Gan, R. Y., Zhang, Y., Xia, E. Q., \& Li, H. B. (2011). Antioxidant capacities and total phenolic contents of 62 fruits. Food Chemistry, 129(2), 345-350.

[45] Gil, M. I., Tomás-Barberán, F. A., Hess-Pierce, B., \& Kader, AA. (2002). Antioxidant capacities, phenolic compounds, carotenoids, and vitamin C contents of nectarine, peach, and plum cultivars from California. Journal of Agricultural and Food Chemistry, 50(17), 4976-4982.

[46] Gansch, H., Weber, C. A., \& Lee, C. Y. (2009). Antioxidant capacity and phenolic phytochemiclas in black raspberries. New York State Horticultural Society, 17(1), 20-23.

[47] Pineli, L. L. O., Moretti, C. L., dos Santos, S. M., Campos, A. B., Brasileiro, A., Córdova, A. C., \& Chiarello, M. D. (2011). Antioxidants and other chemical and physical characteristics of two strawberry cultivars at different ripeness stages. Journal of Food Composition and Analysis, 24(1), 11-16. 
[48] Jolić, S. M., Redovniković, I. R., Marković, K., Šipušić, Đ. I., \& Delonga, K. (2011). Changes of phenolic compounds and antioxidant capacity in cocoa beans processing. International Journal of Food Science and Technology, 46(9), 1793-1800.

[49] Baroni, M. V., Naranjo, R. D. D. P., García-Ferreyra, C., Otaiza, S., \& Wunderlin, D. A. (2012). How good antioxidant is the red wine? Comparison of some in vitro and in vivo methods to assess the antioxidant capacity of Argentinean red wines. LWTFood Science and Technology, 47(1), 1-7.

[50] Lee, KW, Lee, HJ, \& Lee, CY. (2002). Antioxidant activity of black te Lee a vs. green tea. Journal of Nutrition, 132(4), 785.

[51] Natella, F., Nardini, M., Belelli, F., \& Scaccini, C. (2007). Coffee drinking induces incorporation of phenolic acids into LDL and increases the resistance of LDL to ex vivo oxidation in humans. The American Journal of Clinical Nutrition, 86(3), 604-609.

[52] Pellegrini, N., Serafini, M., Colombi, B., Del Rio, D., Salvatore, S., Bianchi, M., \& Brighenti, F. (2003). Total antioxidant capacity of plant foods, beverages and oils consumed in Italy assessed by three different in vitro assays. Journal of Nutrition, 133(9), 2812-2819.

[53] Thiagarajan, G., Chandani, S., Sundari, C. S., Rao, S. H., Kulkarni, A. V., \& Balasubramanian, P. (2001). Antioxidant properties of green and black tea, and their potential ability to retard the progression of eye lens cataract. Experimental Eye Research, 73(3), 393-401.

[54] King, A., \& Young, G. (1999). Characteristics and occurrence of phenolic phytochemicals. Journal of the American Dietetic Association, 99(2), 213-218.

[55] Handelman, G. J., Cao, G., Walter, M. F., Nightingale, Z. D., Paul, G. L., Prior, R. L., \& Blumberg, J. B. (1999). Antioxidant capacity of oat (Avena sativa L.) extracts. 1. Inhibition of low-density lipoprotein oxidation and oxygen radical absorbance capacity. Journal of Agricultural and Food Chemistry, 47(12), 4888-4893.

[56] Jaiswal, A. K., Abu-Ghannam, N., \& Gupta, S. (2012). A comparative study on the polyphenolic content, antibacterial activity and antioxidant capacity of different solvent extracts of Brassica oleracea vegetables. International Journal of Food Science and Technology, 47(2), 223-231.

[57] Vieira, F. G. K., Borges, G. S. C., Copetti, C., Pietro, P. F., Nunes, E. C., \& Fett, R. (2011). Phenolic compounds and antioxidant activity of the apple flesh and peel of eleven cultivars grown in Brazil. Scientia Horticulturae, 128(3), 261-266.

[58] Mitić, M. N., Obradović, M. V., Kostić, D. A., Micić, R. J., \& Pecev, E. T. (2012). Polyphenol content and antioxidant activity of sour cherries from Serbia. Chemical Industry and Chemical Engineering, 18(1), 53-62.

[59] Çekiç, Ç., \& Özgen, M. (2010). Comparison of antioxidant capacity and phytochemical properties of wild and cultivated red raspberries (RubusidaeusL.). Journal of Food Composition and Analysis, 23(6), 540-544. 
[60] Rupasinghe, H. P. V., Jayasankar, S., \& Lay, W. (2006). Variation in total phenolics and antioxidant capacity among European plum genotypes. Scientia Horticulturae, 108(3), 243-246.

[61] Khallouki, F., Haubner, R., Erben, G., Ulrich, C. M., \& Owen, R. W. (2012). Phytochemical composition and antioxidant capacity of various botanical parts of the fruits of Prunus $\times$ domestica L. from the Lorraine region of Europe. Food Chemistry, 133(3), 697-706.

[62] Sánchez, A. C. G., Gil-Izquierdo, A., \& Gil, M. I. (2003). Comparative study of six pear cultivars in terms of their phenolic and vitamin $C$ contents and antioxidant capacity. Journal of the Science of Food and Agriculture, 83(10), 995-1003.

[63] Fischer, U. A., Carle, R., \& Kammerer, D. R. (2011). Identification and quantification of phenolic compounds from pomegranate (Punica granatum L.) peel, mesocarp, aril and differently produced juices by HPLC-DAD-ESI/MS. Food Chemistry, 122(2), 807-821.

[64] Jayaprakasha, G. K., Girennavar, B., \& Patil, B. S. (2008 ). Radical scavenging activities of Rio Red grapefruits and Sour orange fruit extracts in different in vitro model systems. Bioresource Technology, 99(10), 4484-4494.

[65] Jayaprakasha, G. K., Girennavar, B., \& Patil, B. S. (2008 ). Antioxidant capacity of pummelo and navel oranges: Extraction efficiency of solvents in sequence. Lebenson Wiss Technology, 41(3), 376-384.

[66] Rufino, M. S. M., Alves, R. E., Brito, E. S., \& Pérez-Jiménez, J. (2010). Bioactive compounds and antioxidant capacities of 18 non-traditional tropical fruits from Brazil. Food Chemistry, 121(4), 996-1002.

[67] Contreras-Calderón, J, Calderón-Jaimes, L, Guerra-Hernández, E, \& García-Villanova, B. (2011). Antioxidant capacity, phenolic content and vitamin $C$ in pulp, peel and seed from 24 exotic fruits from Colombia. Food Research International, 44(7), 2047-2053.

[68] Adamson, G. E., Lazarus, A. S., Mitchell, A. E., Prior, R. L., Cao, G., Jacobs, P. H., Kremers, B. G., Hammerstone, J. F., Rucker, R. B., Ritter, K. A., \& Schmitz, H. H. (1999). HPLC method for the quantification of procyanidins in cocoa and chocolate samples and correlation to total antioxidant capacity. Journal of Agricultural and Food Chemistry, 47(10), 4184-4188.

[69] Rivero-Pérez, M. D., Muñiz, P., \& González-Sanjosé, M. L. (2007). Antioxidant profile of red wines evaluated by total antioxidante capacity, scavenger activity, and biomarkers of oxidative stress methodologies. Journal of Agricultural and Food Chemistry, 55(14), 6476-5483.

[70] Moure, A., Cruz, J. M., Franco, D., Domínguez, J. M., Sineiro, J., Domínguez, H., Núñez, M. J., \& Parajó, J. C. (2001). Natural antioxidants from residual sources. Food Chemistry, 72(2), 145-171. 
[71] Lee, K. W., Kim, Y. J., Lee, H. J., \& Lee, C. Y. (2003). Cocoa has more phenolic phytochemicals and a higher antioxidant capacity than teas and red wine. Journal of Agricultural and Food Chemistry, 51(25), 7292-7295.

[72] Bravo, J., Monente, C., Juániz, I., Peña, M. P., \& Cid, C. (2011). Influence of extraction process on antioxidant capacity of spent coffee. Food Research International, doi: 10.1016/j.foodres.2011.04.026.

[73] Duthie, G. G., Duthie, S. J., \& Kyle, J. A. M. (2000). Plant polyphenols in cancer an heart disease: implications as nutritional antioxidants. Nutrition Research Reviews, 13(1), 79-106.

[74] Giada, M. L. R., \& Mancini-Filho, J. (2009). Antioxidant capacity of the striped sunflower (Helianthus annuus L.) seed extracts evaluated by three in vitro methods. International Journal of Food Sciences and Nutrition, 60(5), 395-401. 